\title{
Areas of high energy efficiency of energy supply systems with cogeneration heat pump installations of small power and peak electric boilers
}

\author{
O. P. Ostapenko \\ Department of Heat Power Engineering, Vinnytsia National Technical University, Vinnytsia, Ukraine \\ Corresponding author. E-mail: ostapenko1208@gmail.com
}

Paper received 09.12.17; Revised 13.12.17; Accepted for publication 15.12.17.

https://doi.org/10.31174/SEND-NT2017-148V16-23

\begin{abstract}
The approach, aimed at determination of the areas and modes of high energy efficiency of energy supply systems (ESS) with cogeneration heat pump installations (CHPI) of small power and peak electric boilers (EB), on conditions of optimal operation modes of CHPI, taking into consideration complex impact of variable operation modes, sources of drive energy for steam compressor heat pump installations (HPI) of small power, with the account of energy losses in the process of generation, supply and conversion of electric energy, is suggested.
\end{abstract}

Keywords: area of high energy efficient operation, energy supply system, cogeneration heat pump installation of small power, steam compressor heat pump installation of small power, peak electric boiler.

Introduction. In recent years a number of investigations, dealing with the efficiency of usage combined cogeneration heat pump installations in thermal schemes of energy supply sources were carried out $[1-12]$. This technology provides the application of combined cogeneration heat pump installations, that enables to reduce the consumption of natural or alternative gas by $30-45 \%$, as compared with boiler installations of the equivalent capacity [1], and obtain cheaper at cost electric energy, as compared with the grid energy (by $30-40 \%$ ). Cogeneration drive of HPI compressors can be provided on the base of gas engines-generators, manufactured by Ukrainian enterprises.

Publications review on the subject. In research [2 3] energy advantages are evaluated and efficient real operation modes of HPI with electric and cogeneration drives are determined, with the account of the impact of drive energy sources of steam compressor heat pumps and energy losses in the process of generation, supply and conversion of electric energy to HPI. In research [4 - 5] methodical fundamentals of comprehensive assessment of energy efficiency of steam compressor heat pump plants (HPP) with electric and cogeneration drives, with the account of complex impact of HPP variable operation modes, peak sources of heat of HPP, sources of HPP drive energy and with the account of energy losses in the process of generation, supply and conversion of electric energy are suggested. In [5-6] scientific fundamentals are suggested and comprehensive assessment of energy efficiency of steam compressor HPP with cogeneration drive with the account of complex impact of HPP variable operation modes, HPP peak sources of heat, sources of drive energy of steam compressor HPP of various power levels, with the account of energy losses in the process of generation, supply and conversion of electric energy is performed. In research [7] the assessment of ESS energy efficiency on the base of combined CHPI are realized, efficient operation modes of ESS with the account of complex impact of variable operation modes, sources of drive energy of steam compressor HPI of various power levels, with the account of energy losses in the processes of generation, supply and conversion of electric energy are determined. In research [8] energy efficiency of ESS, based on combined CHPI and peak sources of heat (PSH) is evaluated, efficient operation modes of these ESS with the account of complex impact of variable operation modes, sources of drive energy for steam compressor HPI of various power levels, with the account of energy losses in the process of generation, supply and conversion of electric energy are determined. In research [9] methodical fundamentals are developed, assessment of energy efficiency of energy supply systems with combined CHPI and PSH, on conditions of optimal operation modes of CHPI for heat supply systems is performed, energy efficient operation modes of ESS with CHPI and PSH with the account of complex impact of variable operation modes, sources of drive energy for steam compressor HPI of various power levels, with the account of energy losses in the process of generation, supply and conversion of electric energy, is performed.

In accordance with [8 - 9], optimal distribution of loading between CHPI and PSH (for instance, hot-water fuel-fired boiler, electric boiler, solar collectors, etc.) within the frame of ESS largely determines energy efficiency of the above-mentioned ESS. Such distribution is characterized by the share of CHPI loading within the frame of ESS $\beta$, that is determined as the ratio of thermal capacity of CHPI to thermal capacity of ESS $\beta=\mathrm{Q}_{\mathrm{CHPI}} / \mathrm{Q}_{\mathrm{ESS}}$. In the paper [8] it is suggested to realize comprehensive assessment of ESS with CHPI and PSH energy efficiency by complex dimensionless criterion of energy efficiency:

$$
K_{E S S}=(1-\beta) \cdot K_{P S H}+\beta \cdot K_{C H P I}
$$

where $K_{P S H}-$ dimensionless criterion of energy efficiency of peak source of heat within ESS (hot-water fuelfired boiler (FB), electric boiler (EB), solar collectors, etc.) from the researches $[8-9,11-12]$,

$\mathrm{K}_{\mathrm{CHPI}}$ - dimensionless criterion of CHPI within ESS energy efficiency from the researches [2, $7-8]$.

In research [8] spheres of energy efficiency operation of CHPI of various power levels, obtained on the base of the research [7] and determined by CHPI energy efficiency dimensionless criterion $K_{C H P I}$, depending on real values of HPI coefficient of performance $\varphi_{\mathrm{r}}$ and efficient factor of gas-piston engine-generator (GPE) $\eta_{\mathrm{EGPE}}$. Energy efficient operation modes of CHPI correspond to the condition $K_{C H P I}>1$.

Dimensionless criterion of energy efficiency of peak source of heat - electric boiler - within ESS $K_{P S H}$, according to [8], obtained on the base of energy balance 
equation for the systems «Source of electric energy electric boiler - heat consumer from ESS», with the account of the impact of the energy sources for peak electric boiler and with the account of energy losses in the process of generation and supply of electric energy to electric boiler. In research [8], assessment of peak electric boiler energy efficiency in ESS, in case of electric energy usage from CHPI and for the cases of electric energy consumption from energy system, based on conventional or alternative sources of electric energy on the base of steam-gas installations, gas-turbine installations, solar power plants of thermodynamic cycle, wind energy plants is carried out.

High values of energy efficiency dimensionless criterion for ESS with CHPI, obtained in [8], confirm high energy efficiency of such combined energy supply systems. In [9] it is determined that energy efficiency of ESS with CHPI and peak electric boilers almost two times exceeds the energy efficiency of modern high efficient electric and fuel-fired boilers, intended for operation in heat supply systems.

In research [11] methodical fundamentals are developed, spheres of energy efficient operation of ESS with CHPI and PSH, on conditions of CHPI optimal operation modes are determined, energy efficient operation modes of ESS with CHPI and PSH are determined, with the account of complex impact of variable operation modes, sources of drive energy for steam compressor HPI of different power levels, with the account of energy losses in the process of generation, supply and conversion of electric energy. In research [11] on conditions of $K_{C H P I}>1$ and $K_{E S S}>\eta_{E B}$ and modes of energy efficient operation of CHPI, areas of energy efficient operation and energy efficient operation modes of ESS with CHPI and peak electric boilers with different variants of electric energy sources for peak electric boiler, for different levels of ESS elements energy efficiency are determined. It is determined, that ESS with CHPI and peak electric boilers, suggested in the research [11], will be energy efficient, if the share of CHPI loading in ESS will be $\beta>0,7$. Under these conditions, the above-mentioned ESS can be recommended as energy efficient energy supply systems. In research [12] methodical fundamentals are developed, spheres of energy efficient operation of ESS with CHPI and PSH in heat supply systems, on conditions of CHPI optimal operation modes are determined, energy efficient operation modes of ESS with CHPI and PSH in heat supply systems are determined, with the account of complex impact of variable operation modes, sources of drive energy for steam compressor HPI of different power levels, with the account of energy losses in the process of generation, supply and conversion of electric energy.

In $[1-12]$ the authors did not determine the areas of high energy efficiency of energy supply systems with combined CHPI of small power and peak EB, on conditions of optimal operation modes of CHPI.

Objective. Aim of the research is the determination of the areas of high energy efficiency of ESS with CHPI of small power and peak EB on conditions of optimal operation modes of CHPI, determination of high energy efficient operation modes of ESS with CHPI of small power and peak EB with the account of complex impact of variable operation modes, sources of drive energy for steam compressor HPI of small power, with the account of energy losses in the process of generation, supply and conversion of electric energy.

Materials and methods. The research contains the evaluation of high energy efficient operation modes of ESS with CHPI of small power and peak EB. Energy efficiency of ESS with steam compressor HPI of small power (up to $1 \mathrm{MW}$ ) with cogeneration drive from GPE was studied. Electric boiler houses were provided to be used as peak sources of heat in ESS. The investigated ESS with CHPI of small power and peak EB can completely or partially provide auxiliary needs in electric energy and provide the consumers needs in heating and hot water supply. Schemes of the ESS with CHPI and peak EB are presented in works [1, 10]. Methodical fundamentals of energy efficiency evaluation of ESS with CHPI and peak EB are given in research [8].

Areas of high energy efficiency of ESS with CHPI of small power and peak EB can be determined from the dependences, suggested in the research [11 - 12], on conditions of $K_{C H P I}>1$ and $K_{E S S}>1$ [11]. If the abovementioned conditions are realized, the investigated ESS with CHPI of small power and peak EB can be recommended as high energy efficient ESS that can be competitive with modern high-efficient electric and fuel-fired boilers in heat supply and energy supply systems.

In our study the areas of high energy efficiency of ESS with CHPI of small power and peak EB are defined on conditions of optimal operation modes of CHPI on the base of the research, carried out [7-8].

Results and discussion. Application of the suggested approaches, aimed at determination of the areas of ESS with CHPI of small power and peak EB high energy efficiency will be demonstrated on the specific examples. Figs. $1-3$ shows the results of research, aimed at determination of the areas of high energy efficiency of ESS with CHPI of small power and peak EB for energy efficient operation modes of CHPI, based on the results of the studies [7 - 8]. The values of dimensionless criterion of ESS with CHPI of small power and EB energy efficiency for the cases of variable loading of CHPI within ESS on condition of CHPI share change within the range $\beta=0,1 \ldots 1,0$ are determined. As above mentioned, the areas of high energy efficiency of ESS with CHPI of small power and peak EB can be determined on conditions of $K_{C H P I}>1$ and $K_{E S S}>1$ [11]. The research is carried out for energy efficient operation modes of small power CHPI with $K_{C H P I}=1,1 \ldots 2,1$ (on conditions of maximum efficiency of GPE) and with $K_{C H P I}=1,1 \ldots 1,6$ (on conditions of minimum efficiency of GPE), based on the results of the studies [7 - 8]. The above-mentioned values of CHPI $K_{C H P I}$ energy efficiency criterion correspond to the values of real coefficient of performance of CHPI within the limits of $\varphi_{r}=3,0 \ldots 5,4$ for CHPI of small power, according to [8].

Fig. 1 shows the area of high energy efficiency of ESS with CHPI of small power and peak electric boiler, on condition of electric energy consumption by electric boiler from energy system of Ukraine. In the given research, according to $[2,7]$, the following values are taken into account: averaged value of the efficiency factor of 
Ukrainian electric power plants (EPP) $\eta_{E P P}=0,383$ and efficiency factor value of distributive electric grids in Ukraine $\eta_{D G}=0,875$. For these conditions, electric boiler house with $\eta_{E B}=0,95$ is provided to be peak source of heat in ESS.

In case of efficiency factor of electric boiler house change in the range $\eta_{E B}=0,9 \ldots 0,95$ the value of dimensionless criterion of electric boiler energy efficiency for the cases of electric energy consumption from energy system will be $K_{P S H}^{E S}=0,302 \ldots 0,318$. On conditions of $K_{\text {CHPI }}>1$ and $K_{\text {ESS }}>1$ dependences, suggested in the given research, determine the areas of high energy efficient operation of the studied ESS.

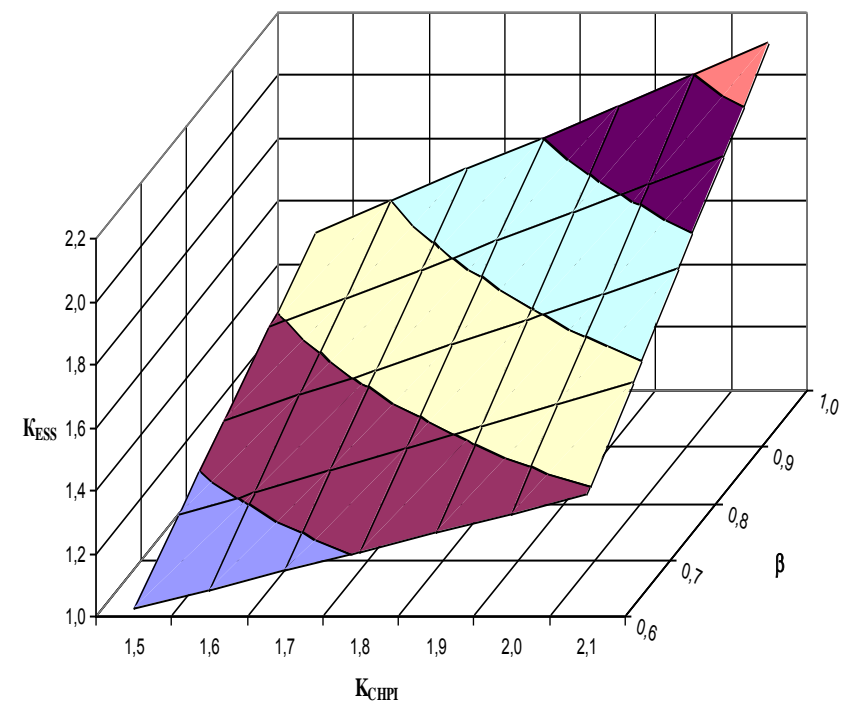

Fig. 1 - Area of high energy efficiency of ESS with CHPI of small power and peak electric boiler, on condition of electric energy consumption by electric boiler from energy system of Ukraine

As it is seen from Fig. 1, the values of complex dimensionless criterion of ESS energy efficiency are $K_{\mathrm{ESS}}=1,03 \ldots 1,5$ on condition of minimal value of energy efficiency criterion of CHPI $K_{C H P I}=1,5$; for operation modes of ESS with $K_{C H P I}>1,5$ the values of dimensionless criterion of ESS energy efficiency change within the limits of $K_{\text {ESS }}=1,09 \ldots 2,1$. High energy efficient operation modes of these ESS are provided on conditions of energy efficient operation modes of CHPI with the values of energy efficiency index $K_{C H P I}=1,5 \ldots .2,1$.

As it is seen from Fig. 1, on conditions of $K_{C H P I}>1,5$ and $K_{E S S}>1$ [11], dependence, shown in Fig. 1, determine area of high energy efficiency of ESS with CHPI of small power and peak electric boiler (boiler house), on condition of electric energy consumption by electric boiler from energy system of Ukraine.

The investigated ESS with CHPI of small power and peak EB, on condition of electric energy consumption by electric boiler from energy system of Ukraine, can be recommended as high energy efficient ESS, that can be competitive with modern high efficient electric and fuelfired boilers in heat supply and energy supply systems, as their efficiency more than two times exceeds energy effi- ciency of modern high efficient electric and fuel-fired boilers.

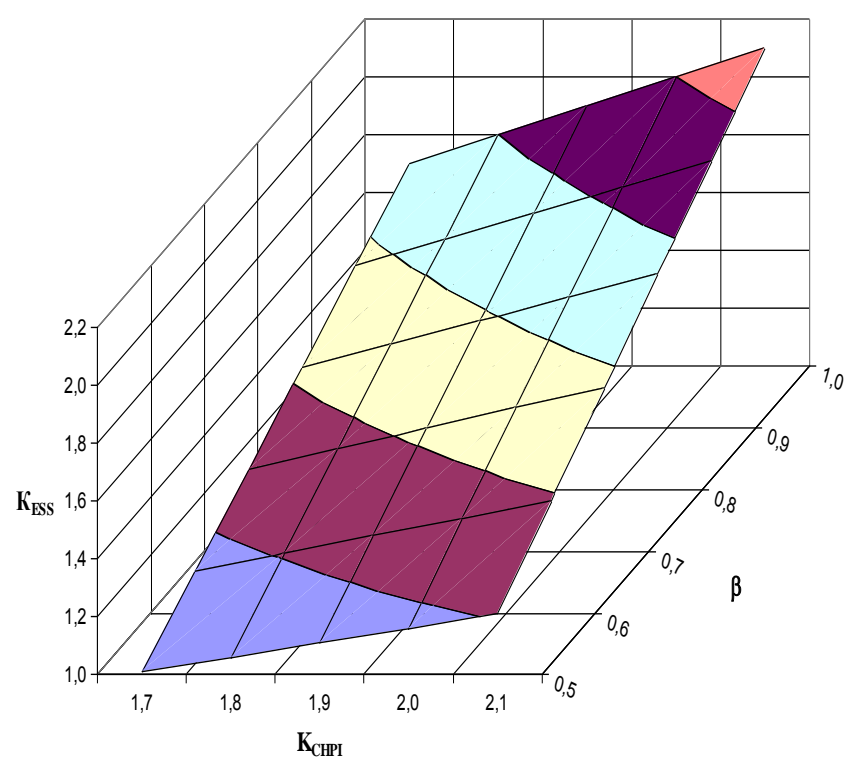

Fig. 3 - Area of high energy efficiency of ESS with CHPI of small power and peak electric boiler, on conditions of maximal efficiency of GPE and EB, with the consumption of electric energy by peak electric boiler from CHPI

Fig. 2 shows the area of high energy efficiency of ESS with CHPI of small power and peak electric boiler house, on conditions of minimal efficiency of GPE and EB, with the consumption of electric energy by peak source of heat (electric boiler) from CHPI. In the given research, in accordance with $[2,7]$, the following values are taken into account: value of GPE efficiency factor $\eta_{\mathrm{EGPE}}=0,31$ and value of electric motor efficiency factor with the account of energy losses in the control unit of electric motor $\eta_{\mathrm{ED}}=0,8$. Electric boiler house with $\eta_{E B}=0,9$ is provided to be peak source of heat in ESS for these conditions.

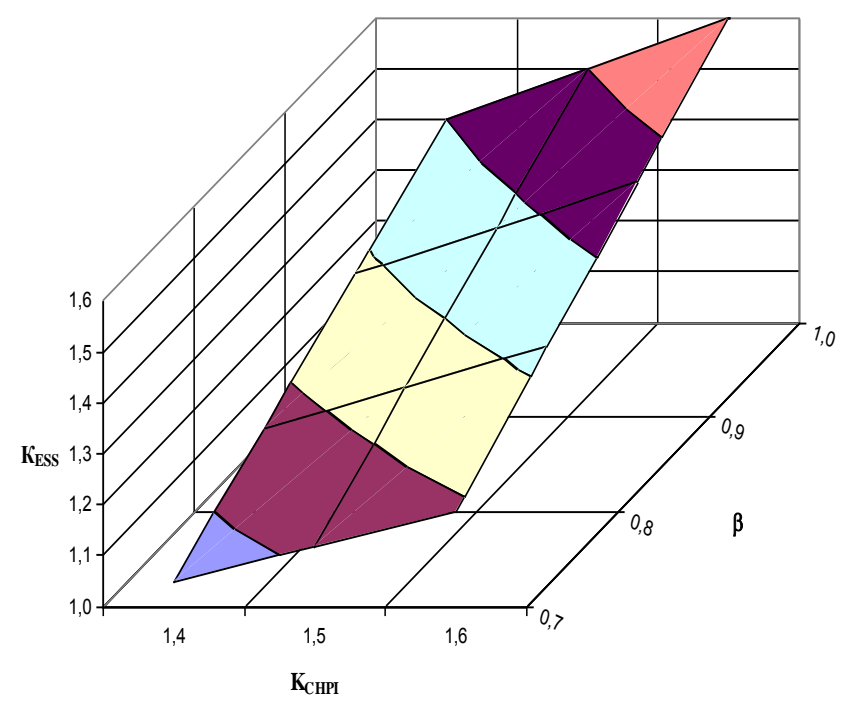

Fig. 2 - Area of high energy efficiency of ESS with CHPI of small power and peak electric boiler house, on conditions of minimal efficiency of GPE and EB, with the consumption of electric energy by peak electric boiler from CHPI 
The value of dimensionless criterion of energy efficiency of electric boiler for the cases of electric energy consumption from CHPI will be $K_{P S H}^{E C}=0,223$.

As it is seen from Fig. 2, the values of complex dimensionless criterion of ESS energy efficiency are $K_{\text {ESS }}=1,05 \ldots 1,4$ on condition of minimal value of energy efficient criterion of CHPI $K_{C H P I}=1,4$; for operation modes of ESS with $K_{C H P I}>1,4$ the values of dimensionless criterion of ESS energy efficiency change in the limits $K_{\text {ESS }}=1,12 \ldots 1,6$. High energy efficient operation modes of these ESS are provided on conditions of energy efficient modes of CHPI operation with the values of energy efficiency index $K_{C H P I}=1,4 \ldots 1,6$.

As it is seen from Fig. 2, on conditions of $K_{C H P I}>1,4$ and $K_{E S S}>1$ [11], dependence, shown in Fig. 2, determine area of high energy efficiency of ESS with CHPI of small power and peak electric boiler (boiler house), on conditions of minimal efficiency of GPE and electric boiler (boiler house), with the consumption of electric energy by peak source of heat (electric boiler) from CHPI. On these conditions, the above-mentioned ESS can be recommended as high energy efficient systems of energy supply, as their efficiency almost two times exceeds energy efficiency of high efficient electric and fuel-fired boilers. Such ESS could be competitive with modern high efficient electric and fuel-fired boilers in the systems of heat and energy supply.

Fig. 3 shows the area of high energy efficiency of ESS with CHPI of small power and peak electric boiler, on conditions of maximal efficiency of GPE and EB, with the consumption of electric energy by peak electric boiler from CHPI. In the given research, according to [2, 7], the following values are taken into account: value of GPE efficiency factor $\eta_{\mathrm{EGPE}}=0,42$ and value of electric motor efficiency with the account of energy losses in the control unit of electric motor $\eta_{\mathrm{ED}}=0,8$. Electric boiler house with $\eta_{E B}=0,95$ is provided to be peak source of heat in ESS for these conditions. The value of dimensionless criterion of electric boiler energy efficiency for the cases of electric energy consumption from CHPI will be $K_{P S H}^{E C}=0,319$.

As it is seen from Fig. 3, the values of complex dimensionless criterion of ESS energy efficiency are $K_{\text {ESS }}=1,01 \ldots 1,7$ on condition on minimal efficient value of energy efficient criterion of CHPI $K_{C H P I}=1,7$; for operation modes of ESS with $K_{C H P I}>1,7$ the values of dimensionless criterion of ESS energy efficiency change within the limits of $K_{\mathrm{ESS}}=1,06 \ldots 2,1$. High energy efficient operation modes of these ESS are provided on conditions of energy efficient modes of CHPI operation with the values of energy efficiency index $K_{C H P I}=1,7 \ldots 2,1$.

As it is seen from Fig. 3, on conditions of $K_{C H P I}>1,7$ and $K_{E S S}>1$ [11], dependence, shown in Fig. 3, determine area of high energy efficiency of ESS with CHPI of small power and peak electric boiler (boiler house), on conditions of maximal efficiency of GPE and electric boiler (boiler house), with the consumption of electric energy by peak source of heat (electric boiler) from CHPI. On such conditions, the above-mentioned ESS can be recommended as high energy efficient energy supply systems, as their efficiency more than two times exceeds energy efficiency of high efficient electric and fuel-fired boilers. The studied ESS can be competitive with modern high efficient electric and fuel-fired boilers in heat and energy supply systems.

It is determined, that ESS with CHPI of small power and peak electric boilers, suggested in the research, will be high energy efficient, if the share of CHPI loading in ESS will be $\beta>0,5 \ldots 0,7$ (depending on sources of drive energy for steam compressor CHPI and various ESS elements energy efficiency) and the value of energy efficient criterion of CHPI will be $K_{C H P I}>1,4 \ldots 1,7$ (depending on sources of drive energy for steam compressor CHPI and various ESS elements energy efficiency); that corresponds to the results of research, shown in Figs. 1-3. At these conditions the areas of high energy efficiency of the above-mentioned ESS are determined. Under realization of these conditions, modern high efficient electric and fuel-fired boilers will be inferior by energy efficiency to the above-mentioned ESS.

Under such conditions, the above-mentioned ESS with CHPI of small power and peak electric boilers can be recommended as high efficient energy supply systems, as even in case of minimal efficiency of GPE and electric boiler, energy efficiency of ESS almost two times exceeds energy efficiency of high efficient electric and fuel-fired boilers. This ESS can be competitive with modern high efficient electric and fuel-fired boilers in the systems of heat and energy supply.

Conclusions. Areas of high energy efficiency of ESS with CHPI of small power and peak EB, on conditions of optimal operation modes of CHPI are determined; high energy efficient operation modes of ESS with small power CHPI and peak EB with the account of complex impact of variable operation modes, sources of drive energy for steam compressor HPI of small power, with the account of energy losses in the process of generation, supply and conversion of electric energy are determined.

The suggested approach, aimed at determination of the areas of high energy efficiency of ESS with CHPI of small power and peak electric boilers has a number of advantages:

- it takes into account variable operation modes of ESS with the change of load distribution between steam compressor CHPI and peak EB in ESS;

- it enables to determine areas and modes of high energy efficient operation of ESS with small power CHPI and peak EB, at which energy efficiency of the studied ESS almost two times exceeds energy efficiency of modern high energy efficient electric and fuel-fired boilers;

- methodical fundamentals, suggested in [8], and the results of research, presented in the given paper, could be used for the determination of the areas of high energy efficient operation of ESS with peak electric boilers and steam compressor CHPI of small power, with various refrigerants, sources of low temperature heat and scheme solutions;

- it allows to develop recommendations, aimed at high energy efficient operation of ESS with small power CHPI and peak EB with different scheme solutions. 
Under conditions of $K_{C H P I}>1,4 \ldots 1,7$ (depending on sources of drive energy for steam compressor CHPI and various ESS elements energy efficiency) and $K_{E S S}>1$ and modes of energy efficient operation of CHPI, areas of high energy efficiency and high energy efficient operation modes of ESS with CHPI of small power and peak electric boilers, for various ESS elements energy efficiency are determined.

It is determined, that ESS with CHPI of small power and peak electric boilers, suggested in the research, will be high energy efficient, if the share of CHPI loading in ESS will be $\beta>0,5 \ldots 0,7$ (depending on sources of drive energy for steam compressor CHPI and various ESS elements energy efficiency). If this condition is realized, modern high efficient electric and fuel-fired boilers will be inferior by their energy efficiency to the abovementioned ESS.

Under these conditions the above-mentioned ESS with CHPI of small power and peak electric boilers can be recommended as high energy efficient ESS, as even in case of minimal efficiency of GPE and electric boiler, energy efficiency of ESS almost two times exceeds energy efficiency of high efficient electric and fuel-fired boilers. This ESS can be competitive with modern high efficient electric and fuel-fired boilers in the systems of heat and energy supply.

\section{REFERENCES}

1. Tkachenko, S. Y.; Ostapenko, O. P. Steam compressor heat pump installations in heat supply systems, monograph, Vinnytsia : UNIVERSUM-Vinnytsia, 2009, 176 p. (in Ukrainian)

2. Ostapenko, O. P.; Leshchenko, V. V.; Tikhonenko, R. O. Energy efficiency of steam compressor heat pumps with electric and cogeneration drive, electronic resource, Scientific Works of Vinnytsia National Technical University, 2014, №4, available at: http://works.vntu.edu.ua/index.php/works/article/view/25/25.

3. Ostapenko, O. P.; Leshchenko, V. V.; Tikhonenko, R. O. Energy advantages of application of steam compressor heat pumps with electric and cogeneration drive, electronic resource, Scientific Works of Vinnytsia National Technical University, 2015, №1, available at: http://works.vntu.edu.ua/index.php/works/ article/view/437/435.

4. Ostapenko, O. P. Methodical fundamentals of complex assessment of energy efficiency of steam compressor heat pump plants with electric and cogeneration drive, Scientific Works of Odesa National Academy of Food Technologies, 2015, vol. 47, part 2, p. 157 - 162. (in Ukrainian)

5. Ostapenko, O.P. Scientific basis of evaluation energy efficiency of heat pump plants, monograph, Saarbrücken, LAP LAMBERT Academic Publishing, 2016, 64 p.

6. Ostapenko, O. P. Complex evaluation of energy efficiency of steam compressor heat pump plants with cogeneration drive, electronic resource, Scientific Works of Vinnytsia National Technical University, 2015, №3, available at: http://works.vntu.edu.ua/index.php/works/article/view/36/36.

7. Ostapenko, O. P.; Leshchenko, V. V.; Tikhonenko, R. O. Energy efficiency of energy supply systems, based on combined cogeneration heat pump installations; electronic resource,
Scientific Works of Vinnytsia National Technical University, 2015, №4, available at: http://works.vntu.edu.ua/index.php/ works/article/view/451/453.

8. Ostapenko, O. P. Energy efficiency of energy supply systems, based on combined cogeneration heat pump installations and peak sources of heat; electronic resource, Scientific Works of Vinnytsia National Technical University, 2016, № 1, available at: http://works.vntu.edu.ua/index.php/works/article/view/ $462 / 464$

9. Ostapenko, O. P. Energy efficiency of energy supply systems with cogeneration heat pump installations and peak sources of heat in heat supply systems, electronic resource, Scientific Works of Vinnytsia National Technical University, 2016, № 2, available at: http://works.vntu.edu.ua/index.php/ works/article/view/472/474.

10. Ostapenko, O. P. Refrigeration equipment and technology. Heat pumps, tutorial, Vinnytsia : VNTU, 2015, 123 p. (in Ukrainian)

11. Ostapenko, O.P. Spheres of energy efficiency operation of energy supply systems with cogeneration-heat pump installations and peak sources of heat, electronic resource, Scientific Works of Vinnytsia National Technical University, 2016, № 3, available at: http://works.vntu.edu.ua/index.php/ works/article/view/479/481.

12. Ostapenko, O.P. Spheres of energy efficient operation of energy supply systems with cogeneration-heat pump installations and peak sources of heat in heat supply systems, electronic resource, Scientific Works of Vinnytsia National Technical University, 2016, № 4, available at: https://works.vntu.edu.ua/index.php/works/article/view/487/4 89.

\footnotetext{
Области высокой энергоэффективности систем энергоснабжения с когенерационно-теплонасосными установками малой мощности и пиковыми электрическими котлами

О. П. Остапенко

Аннотация: Предложен подход по определению областей и режимов высокой энергоэффективности систем энергоснабжения (СЭ) с когенерационно-теплонасосными установками (КТНУ) малой мощности и пиковыми электрическими котлами (ЭК), при условиях оптимальных режимов работы КТНУ, с учетом комплексного влияния переменных режимов работы, источников приводной энергии для парокомпрессионных теплонасосных установок (ТНУ) малой мощности, с учетом потерь энергии при генерировании, снабжении и преобразовании электрической энергии.

Ключевые слова: область высокой энергоэффективности, система энергоснабжения, когенерационно-теплонасосная установка малой мощности, парокомпрессионная теплонасосная установка малой мощности, пиковый электрический котел.
} 